\title{
A Petri Net-based Supply Chain System
}

\author{
https://doi.org/10.3991/ijoe.v14i11.9502 \\ Jiang-ping Liu, Ri-geng $\mathrm{Wu}$ \\ Mongolia Agricultural University, Huhot, China \\ jiangpingliu12930@163.com
}

\begin{abstract}
In order to solve the problem of supply of agricultural products, the current mode of decentralized agricultural product supply is described with the Petri net formalized modeling method. A corresponding Petri net model is established. Based on this, combined with mathematical methods, the supply chain is divided into different links, and a quantitative analysis of the operation cycle and the operational efficiency of each link is carried out. The construction of the program has changed the previous scattered farmer operating model, integrated the information of farmers and related products, and completed the production and processing of agricultural products in the form of task distribution. The circulation of information in the entire supply chain has been realized, thus ensuring the production benefits of each farmer, reducing the previous business risks that a single farmer needs to bear, and improving the operational efficiency of the entire supply chain.
\end{abstract}

Keywords-informatization, Petri net, supply chain, information circulation

\section{$1 \quad$ Introduction}

The rise of supply chain ideas emerged after the 1990s, and its purpose was to transform the traditional management model of "highly self-control". This strategy adopted by the traditional management model often makes a company need to include all production, processing, transportation and sales activities of the product, resulting in a greater risk to be faced and undertaken by a single company. At the same time, it also increased the investment burden of the company and failed to create the maximum value generated by the product during the entire circulation process. The emerging supply chain management model emphasizes the overall integration idea and pays attention to the spirit of cooperation. It regards all links in the product distribution process as a whole. It leverages modern information and management technologies to integrate processes between business partners in the supply chain, and effectively manages the entire process of product supply chain from raw material production, processing, sales, to the final delivery to the user. Through the combination with modern information management ideas, the supply chain management ideology and organizational model can make full use of the company's internal and external resources, reduce the investment of individual enterprises, reduce the burden on enterprises, and ensure the circulation of 
products, thus forming a strong market competitiveness, jointly undertaking the risks of the enterprise, and maximizing the economic benefits of the enterprise.

In theoretical research, the idea of combining supply chain and agricultural products in previous research work is inherited, and the formal modeling method of Petri nets in software engineering methodology is introduced into the actual research of agricultural products supply chain. The method of Petri net modeling is used to describe the current supply chain management model of agricultural products in China. The quantitative analysis of each link of supply chain management is carried out in conjunction with the mathematical method. The research theory of Petri Net-based agricultural product supply chain system construction scheme is put forward.

Its practical application value lies in that Petri net-based modelling of agricultural product supply chain is implemented. A detailed plan for the construction of China's supply chain management information system is proposed for each link in the current supply chain. And through Petri net modeling analysis, the constructed supply chain management information system is compared with the current fragmented agricultural product supply chain model. It shows that the establishment of this system has improved the operation of China's agricultural product supply chain, can effectively shorten the operation cycle of the entire supply chain, and improve the operational efficiency of the supply chain.

\section{Literature review}

\subsection{Overview of supply chain management research}

In today's globalized operation, with the continuous refinement of the division of labor, both international multinational corporations and domestic large and mediumsized enterprise partners have more and more cooperation. At the same time, more complex and frequent inter-enterprise resource flows and collaboration are also needed. Therefore, how to control the complex and frequent resources flow within enterprises and between enterprises and enterprises and coordinate the relationship between information, capital, and interests of enterprises is a key issue for enterprises to obtain competitive advantages. This is also the reason why "supply chain management" has caused extensive research and discussion.

Reefke and Sundaram (2017) believe that the research direction of supply chain management tends to seek to find a close relationship between customers, suppliers and other related organizations to create a competitive advantage; the supply chain is a system of material supply, manufacturing units, distribution services, and consumers. They are connected by material flow and information flow [1].

Teixeira et al. (2016) proposed that supply chain management is to make reasonable arrangements between suppliers and consumers of materials under the trend of global operation, and to plan and coordinate the distribution of benefits among members in the supply chain. Finally, in the existing conditions, the market entry time should be reduced as much as possible and the service level should be improved [2]. 
Park et al. (2016) used "managing the flow" to define the nature of supply chain management. They believe that supply chain management is the material flow technology that manages the connection of material suppliers and consumers, emphasizing the production from materials to final delivery to consumers [3].

Durach et al. (2017) believe that supply chain management continuously runs through every link of the product value chain. Members on the supply chain coordinate and plan the interests of members through communication and communication to achieve the ultimate goal of the company. Therefore, from the point of view of manufacturing and sales channels, supply chain refers to a product and service system that has a combination of upper reach, middle reach, and downstream members. For example, the downstream is the retailer closest to consumers, the middle reaches are wholesalers, and the upper reaches are manufacturers and suppliers. The ultimate goal of the entire supply chain is to meet the needs of the final consumers [4].

Kherbach and Mocan (2016) believe that supply chain management is a continuous process and should focus on process rather than a certain task. It reduces product entry time and product costs with supply chain management, ultimately meeting customer needs and increasing customer satisfaction [5].

In summary, the core idea of supply chain management is the "system" thinking concept and the "streaming" thinking concept. The supply chain is an overall system. Effective management of the information flow, capital flow, and logistics in this system enables the supply chain established around the core enterprise to be optimized. Supply chain management can achieve the effective operation of all processes in the supply chain from procurement to finished product production to meet the needs of the end customer with the lowest cost and best service level. It delivers the right products to consumers at a reasonable price in a timely manner, ultimately maximizing the benefits of the companies in the supply chain.

\subsection{An overview of supply chain system based on Petri nets}

Petri net theory applied to model establishment is usually divided into two methods: the first method uses Petri nets to establish models directly to make the model close to practical problems and easy to understand. This method usually uses high-level Petri nets for modeling research. Because the high-level Petri net is an intuitive, easy-tounderstand graphics modeling technology. Because the formal modeling method with lower level of basic Petri nets can't describe the actual problem better, the second method uses other formal modeling methods and then transforms it into basic Petri net analysis. Or the second method uses a basic Petri net to build a model and uses other methods to analyze the model. For the above two kinds of Petri net modeling methods, it is difficult to judge which method is better, because different models have different advantages and disadvantages for the same system with different network modeling methods.

Bartoletti et al. (2017) used a generalized Petri net to study a supply chain dynamic construction model technique. Raghavan used a generalized discrete Petri net to analyze the supply chain network. It assumes that the customer order arrival process obeys the Poisson distribution and the service procedures of each service desk obey the 
exponential distribution [6]. The established model takes into account the procurement process and the logistics transfer between the two supply chain members. From the aspect of total cost, performance comparisons are made between the production control strategy of inventory production and order assembly production, and the total cost refers to the cost of warehouse handling and the cost of transportation delay. The formula for the local decoupling point of the supply chain is established, and the minimum total cost, handling cost, and delay cost are solved as objective functions. The GSPN queuing theory model is used as the solution framework for the local decoupling point of the supply chain.

Chen et al. (2017) studied the supply chain system's internal and external uncertainties, especially the external demand uncertainty [7]. Based on the reliability problem, a stochastic colored Petri net is proposed to model and analyze the performance and reliability of the supply chain system under a certain level of demand. A supply chain inventory strategy model is established and Markov chain transfer matrix is used to evaluate the equipment failure probability of the supply chain system. The probability of the equipment failure in the transportation and storage of goods and the decrease of the supply chain reliability are analyzed and calculated.

Liu et al. (2017) used the generalized stochastic Petri net to establish a supply chain model for ordering, production, and sales, and analyzed and evaluated the supply chain model [8]. In the analysis and evaluation, the reachable graph method and Markov supply chain theory are used to analyze the non-manufacturing cycle lead time in the preordering period, which proved the validity of the lead time calculation model. The authors found that there is a quantitative linear relationship between order lead time and supplier service level, which also provides a reference for shortening the supply chain lead time.

In recent years, the Petri net method can effectively solve the synchronization and concurrency problems in discrete dynamic systems. The use of Petri nets in supply chain system modeling and simulation is very extensive. Among them, the high-level Petri net generated by the combination of modeling techniques such as object-oriented methods and basic Petri net theory has achieved good results in describing, controlling and scheduling logistics systems. The combination of the high-level Petri net method and object-oriented technology can solve the reconstruction problem in the members of the variable supply chain system through the structural change algorithm.

\section{$3 \quad$ Petri net basic theory and modeling method}

\subsection{The introduction of Petri Net}

Supply chain is a rather complicated dynamic system, especially the construction of agricultural product supply chain. It contains many links and involved objects. There are dynamic changes in both time and space, and it is also affected by the corresponding decisions. The traditional qualitative analysis method can't accurately describe its operating status. The proposed adjustment scheme lacks data support, which often results 
in the error of decision making and can't accurately reflect the problems in the supply chain movement process.

The method of modeling and simulating in the computer field is an effective scheme for studying such complex dynamic systems. It can simulate and compare the nodes of the supply chain from a quantitative perspective. Therefore, the Petri net modeling method is used to focus on the construction and optimization of agricultural product supply chains. In combination with the rigorous method of mathematics, the operational mechanism of the current agricultural product supply chain management is analyzed as a whole, and the weak links are optimized and restructured to improve the operational efficiency of the supply chain and maximize the benefits of the agricultural product supply chain.

\subsection{Basic definition of Petri net}

Petri net is an important concept in the field of computers and it is a widely used formal method. The difference from the traditional modeling method is that it has a strict mathematical definition, which can provide data support for quantitative research. At the same time, it has a simplified, intuitive graphical representation, which can concisely draw out the operating mechanism of the actual research object. In 1962, the concept of Petri net first appeared in the paper of Dr. Carl Adam Petri, a famous mathematician and computer scientist in Germany. Its basic definition is as follows:

The Petri net structure is a triple $\mathrm{N}=(\mathrm{P}, \mathrm{T}, \mathrm{F})$, where $\mathrm{P}=\left\{\mathrm{P}_{1} . \mathrm{P}_{2} \ldots \mathrm{P}_{8}\right\}$ is a set of finite positions; $\mathrm{T}=\left\{\mathrm{t}_{1} . \mathrm{t}_{2} \ldots \mathrm{t}_{8}\right\}$ is a finite migration set $(\mathrm{P} \cup \mathrm{T} \neq \varnothing, \mathrm{P} \cap \mathrm{T}=\varnothing) ; \mathrm{F} \subseteq(\mathrm{P} \times \mathrm{T})$ $\cap(\mathrm{P} \times \mathrm{T})$ is a stream relationship. In general, in the graphical representation of the Petri net, the position is represented by a circle, the transition is represented by a rectangle, and the flow relationship between position and transition is represented by a directed arc. Its graphic example is shown in Figure 1:

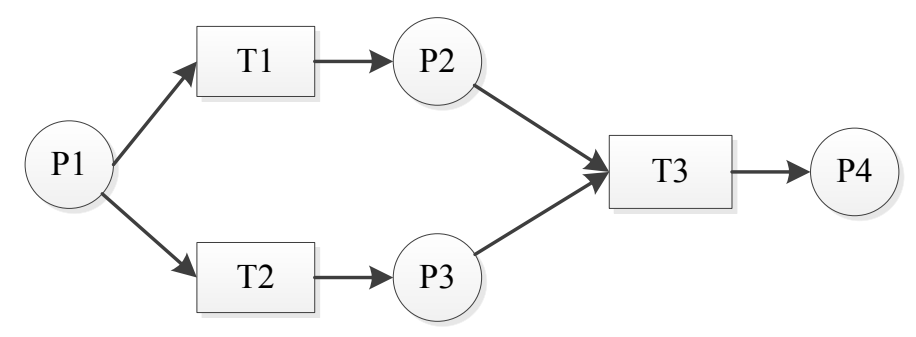

Fig. 1. Petri net structure graphic example

\subsection{Supply chain Petri net modeling and measurement process}

By substituting the above Petri net theory and Markov chain theory into the research process of the supply chain, corresponding research can be conducted through simulation software modeling. A commonly used Java platform-based simulation software Pipe3.0 (Platform Independent Petri Net Editor) is adopted. 
The first step is to establish a model to define the existing state and transition in the operation process of the existing supply chain system, and to describe the meaning of each state and transition. They are represented in the Petri net model by the storehouse $\mathrm{P}$ and transition $\mathrm{T}$, respectively. The last state $\mathrm{P}_{1}$ can only reach the next state $\mathrm{P}_{2}$ after transition $\mathrm{T}_{1}$;

Taking a simple supply chain model in the current status of China's existing agricultural products as an example, the following model shown in Figure 2 can be established in Pipe 3.0:

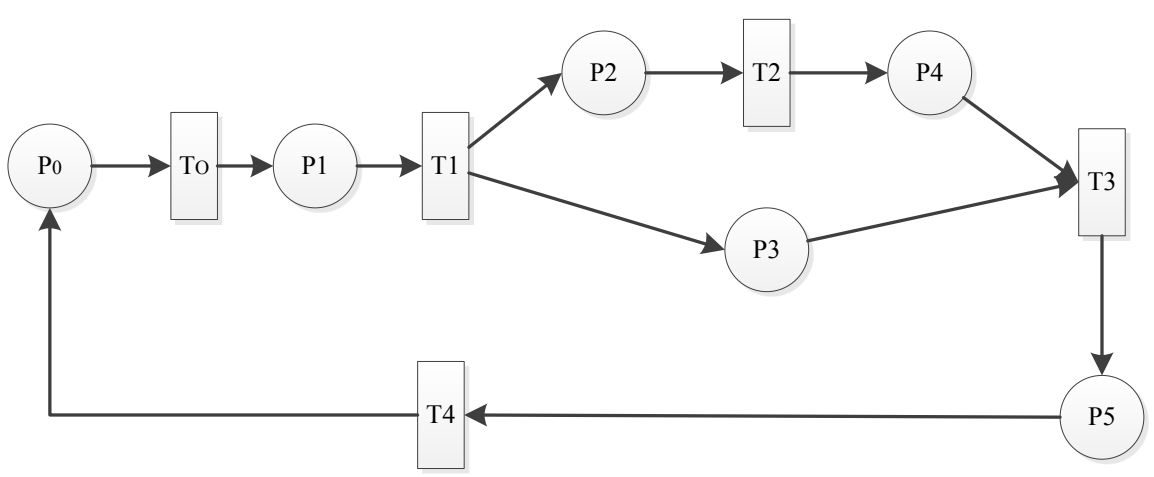

Fig. 2. A supply chain model

As shown in the above diagram, there must be a transition between every two states, and the two are interlocked to form an operational supply chain.

The second step is to do quantitative research. When the assignment of vicissitudes establishes the Petri net model of the supply chain, it needs to add delay to the occurrence of each transition in the model. In the above supply chain model, it is assumed that the delay occurring in each transition $T_{i}$ is $\lambda_{\mathrm{i}}$.

The third step is to build its Markov chain to conduct future quantitative research. According to the Markov chain principle, it is necessary to describe each reachable state $\mathrm{M}_{\mathrm{i}}$ in the supply chain operation process and establish its Markov chain, as shown in Figure 3 below:

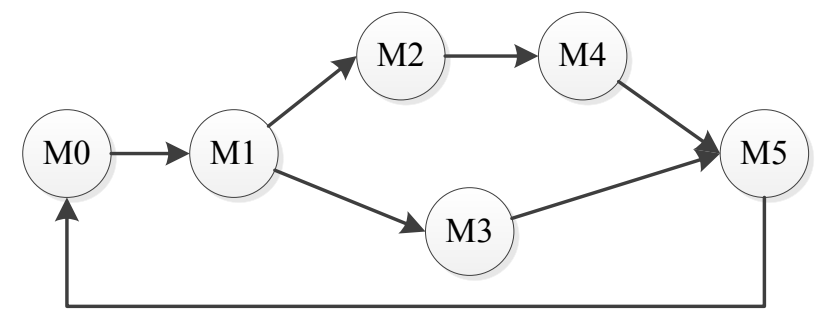

Fig. 3. Markov chain of a supply chain model 
This figure describes each possible state of supply chain operation. When two states $\mathrm{M}_{\mathrm{i}}$ and $\mathrm{M}_{\mathrm{j}}$ are mutually reachable, they are connected by a directed arc and the corresponding transition delay is marked on top of them.

The fourth step is to solve the stability probability of each state. According to the definition of Markov transition matrix Q, its Markov transition matrix is constructed.

It is known that when there is a directed arc from the $M_{i}$ state to the $M_{j}$ state, each element $\mathrm{q}_{\mathrm{ij}}$ in the matrix $\mathrm{Q}$ is the rate value on the arc, and if there is no connection between the two states, $q_{i j}$ is zero. Among them, the diagonal elements are:

$$
q_{i j}=-\sum_{j=1}^{k} q_{i j} .
$$

Next, according to formula (1), solving the system of equations can yield the occurrence probability of each state $\mathrm{P} *\left(\mathrm{M}_{\mathrm{i}}\right)$ during the long-term stable operation of the supply, the steady-state probabilities of the supply chain will be calculated with Pipe 3.0 software.

The fifth step is to calculate the execution time. Finally, according to the balance principle, the average number of tokens required to support the stable operation of the supply chain is divided by the average number of tokens entering the supply chain system within a unit of time, and the supply chain can be obtained. Then the average execution time of the supply chain (that is, the stable operation cycle of the supply chain) can be obtained, and the formula is as follows:

$$
T=N / \lambda \text {. }
$$

Assume that each library has a token with a probability of $\mathrm{P}\left(\mathrm{M}\left(\mathrm{P}_{i}=1\right)\right)$. Its meaning indicates the average probability that the library $P_{i}$ is active. The formula is as follows:

$$
P\left(M\left(P_{i}=1\right)\right)=R_{n n}^{T} * P\left(M_{i}\right) .
$$

The average number of tokens needed for a stable operation of a system $P N=\left\{\mathrm{P}_{1}\right.$, $\left.\mathrm{P}_{2}, \ldots, \mathrm{P}_{n}\right\}$ containing $\mathrm{n}$ libraries is:

$$
N=\sum_{i=1}^{n} P\left(M\left(P_{i}=1\right)\right) .
$$

The larger the value, the more tokens are needed to support the operation of the system, which means that the more support conditions the system needs, the lower the operating efficiency. After the total number of tokens required for the operation of the system is calculated, the average execution time $\mathrm{T}$ of the supply chain is obtained by dividing $\mathrm{N}$ by $\lambda$ according to formula (2).

As mentioned above, Petri nets and Markov chain theory play an important role in the research of agricultural product supply chains. The formal modeling method based on Petri nets will be able to effectively describe the current supply chain model of agricultural products. By introducing time considerations on the basis of the Petri net 
model, the entire supply chain can be quantified in combination with the calculation method of Markov chain mathematics to explain the reasons that affect the current supply chain operations and provide a basis for the reconstruction of the supply chain.

\section{$4 \quad$ Existing product supply chain modeling based on Petri net}

In the existing model of agricultural product supply, the main supply of agricultural products is mainly based on scattered individual agricultural businessmen, while there are few concentrated agricultural product bases. Based on their own understanding of the agricultural product market, these agricultural businessmen conduct production in a decentralized manner. After simple packaging, they transport the products to the bazaar or farmers' market for sale. Due to the limitation of storage conditions and the difficulty of logistics, most of the products are difficult to sell to distant areas, hindering the promotion and circulation of products, and it is extremely unfavorable for long-term development.

Therefore, through the method of Petri net modeling, based on the interrelated changes in information flow, logistics, and capital flow, the current agricultural product supply model is quantitatively studied and compared and analyzed, so that the current supply model of agricultural products can be adjusted with the modern information management technology, ultimately improving the operation efficiency of the entire supply chain and obtaining greater benefits.

Firstly, before the establishment of the operational model of the current agricultural product supply model, a qualitative analysis of its composition is required. It is known that the current supply of agricultural products mainly includes the following links, as shown in Figure 4:

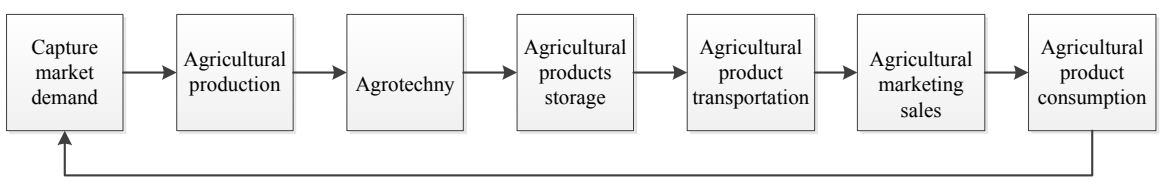

Fig. 4. The link of traditional agricultural product supply model

From acquiring market demand to final agricultural product consumption process, it contains a lot of information such as market demand, product price, production quantity, processing time, inventory, transportation conditions, and market sales. As the main body in the supply chain, manufacturers, processors, logistics companies, retailers, and consumers need to grasp the relevant information in a timely and effective manner and play a role in the corresponding links, thus leading the operation of the entire supply chain.

However, in the existing supply model, due to the lack of effective information platform support, the flow of information between the various links is hindered, resulting in communication difficulties between producers, processors, logistics, and vendors. In the traditional supply model, in order to be able to control effective information, these 
independent agricultural businessmen usually have to undertake all the work of production, processing, transportation and sales, and they sell directly to consumers.

These scattered agricultural businessmen don't need to cooperate with other operators and can independently complete a series of supply chain links from product production to final consumers, so as to obtain all the benefits. Because this kind of supply model is simple in operation and has a direct benefit, individual agricultural businessmen in almost all regions of China are adopting this independent management mode, which has formed the current status of China's current agricultural product supply chain.

Although this supply model has a long history, it can basically maintain the balance of agricultural products supply in China at present, but it has gradually exposed many problems in the information age. At the same time, is it possible to maximize the benefits for this mode of operation? Where are the problems? What are the risks involved? Is it able to adapt to the long-term development of the future agricultural product supply chain? In the absence of relevant quantitative research, this series of questions will be difficult to know only through empirical judgment, and their advantages will not be explained through comparison. Faced with the increasingly fierce competition in the agricultural product market and frequent problems, it is urgently necessary to carry out a comprehensive quantitative analysis of the current supply model so as to improve the current agricultural product supply chain model based on the comparison of research results, improve its operational efficiency, and shorten its operating cycle.

For this reason, in the following work, the method of Petri net modeling will be used to quantitatively study and analyze these problems and provide data support for the reconstruction and optimization of the supply chain.

\section{$5 \quad$ System implementation and test analysis}

\subsection{The implementation and test of system Web foreground}

Firstly, around the realization of the business process of the system Web foreground, related functions such as user registration and login, website product release and display, and order submission processing will be tested.

User's registration and login. When the user needs to publish or browse related product information, it will automatically jump to the login interface, requiring the user to enter the correct user name and password to perform the corresponding operation. If it is already logged in, it will enter the corresponding page and will not pop out of the user login screen.

Agricultural information release. Through the "Product Release" on the homepage, the agricultural businessman or website administrator can publish their own product information on the website. The published interface is shown in Figure 7 below, and it contains the basic attribute information of agricultural products (required with *).

Order submission processing. Through testing, the related attribute information of the interface product is correct, and the user is provided with an interface for shopping 
and inquiry, and the user can enter the order submission interface to place an order by clicking "Buy Now" or "Add to Shopping Cart".

After the order is completed, payment can be made to form a transaction record. At this time, the seller will deliver the product according to the order. After the order is delivered, the order status will be changed to the "Product has been sent" status. Before the delivery, the user can cancel the order.

Up to now, the front-end agricultural product transaction process test is completed, the entire process is performed smoothly, the system has the function of verification and prompting for the user's operation, can effectively help the user to complete the transaction and guide the user's wrong operation. However, due to the fact that the system hasn't been officially released to the space, the connection with online banking hasn't been completed.

\subsection{The implementation and test of system management background}

According to the business needs of the agricultural supply chain management system, functional modules such as warehouse management, task management, agricultural businessman management and system management of the system will be tested. Before testing the background management function, it needs to first enter the background login interface. After the user name and password are input, the system will judge according to the selected "user type" and automatically jump to the specific management module.

Warehouse management. When a "warehouse administrator" type user name and password are entered, the system automatically jumps to the warehouse management function module and selects the "add inventory information" option, where each cell is required information.

Task management. When a "task administrator" type user name and password are entered, the system automatically jumps to the task management function module.

After the "order statistics", "customer statistics" and "inquiry of agricultural information" are performed, the task manager can formulate corresponding production and processing tasks according to market demand.

The management of agricultural businessman. When the user name and password of an "agricultural businessman" type are entered, the system automatically jumps to the agricultural business management function module, in which each agricultural businessman will be able to manage its own information and be able to query related task information.

After the "task administrator" adds tasks, each agricultural businessman can query the sent task information through the system. agricultural businessman can choose whether to accept the task or not, and when the agricultural businessman chooses, the audit status will change to "waiting for review". The task will be generated until the task manager determines. 


\section{Conclusion}

With the advent of the information age, it has brought a good opportunity for the integration of information and industrialization. As China's pillar industry, the development of agriculture is also inseparable from the support of informationization. However, there are still many problems in the agricultural supply model in most of our country. Traditional management ideas and conservative business models have been difficult to maintain the long-term development of our country's agriculture. With the rise of the information industry and increasingly fierce market competition, the traditional agricultural model of decentralized and independent management is bound to be eliminated. The future competition between industries will no longer be the competition among individual enterprises but will fall on the competition among supply chains. Therefore, in order to change China's current agricultural product supply model, a series of studies have been carried out based on Petri net modeling method and Markov chain theory. It hopes to improve China's current agricultural supply model through the combination of supply chain ideas and modern information technology, solve the current problems in China's agricultural supply model, and thus promote the long-term development of China's future agriculturalization.

Combining the formal modeling method of Petri nets in software engineering, China's current agricultural supply model is modeled. A detailed quantitative study has been carried out on a series of supply chain links from market demand acquisition, product production, processing, transportation, sales, and consumption processes of consumer. Through the comparison of quantitative research results, the weak links in the current supply chain model have been pointed out, providing practical data support for the reconstruction of the supply chain.

\section{$7 \quad$ Acknowledgement}

1. National Natural Science Foundation 61582067;

2. Inner Mongolia Agricultural University basic research start-up fund project: JC2015009.

\section{$8 \quad$ References}

[1] Reefke H, Sundaram D. (2017). Key themes and research opportunities in sus-tainable supply chain management - identification and evaluation. Omega, 66: 195-211. https://doi.org/10.1016/j.omega.2016.02.003

[2] Teixeira A A, Jabbour C J C, Latan H. (2016). Green training and green supply chain management: evidence from Brazilian firms. Journal of Cleaner Production, 116(1): 170-176. https://doi.org/10.1016/i.jclepro.2015.12.061

[3] Park K, Min H, Min S. (2016). Inter-relationship among risk taking propensity, supply chain security practices, and supply chain disruption occurrence. Journal of Purchasing \& Supply Management, 22(2): 120-130. https://doi.org/10.1016/j.pursup.2015.12.001 
[4] Durach C F, Kembro J, Wieland A. (2017). A New Paradigm for Systematic Liter-ature Reviews in Supply Chain Management. Journal of Supply Chain Management, 53(4): 6785. https://doi.org/10.1111/jscm.12145

[5] Kherbach O, Mocan M L. (2016). The Importance of Logistics and Supply Chain Management in the Enhancement of Romanian SMEs. Procedia - Social and Behavior-al Sciences, 221: 405-413.

[6] Bartoletti M, Cimoli T, Pinna G M. (2017). Lending Petri Nets and Contracts. Lecture Notes in Computer Science: 8161: 66-82. https://doi.org/10.1007/978-3-642-40213-5_5

[7] Chen Y F, Li Z W, Al-Ahmari A. (2017). Deadlock Recovery for Flexible Manu-facturing Systems Modeled with Petri Nets. Information Sciences, 381(C): 290-303. https://doi.org/10.1016/j.ins.2016.11.011

[8] Liu H, Xing K, Wu W. (2017). Deadlock Prevention for Flexible Manufacturing Systems via Controllable Siphon Basis of Petri Nets. IEEE Transactions on Systems Man \& Cybernetics Systems, 45(3): 519-529.

\section{Authors}

Jiang-ping Liu works as associate professor at College of Computer and Information Engineering of the Inner Mongolia Agricultural University, Huhot 010018, China.

Ri-geng Wu works as associate professor at College of Computer and Information Engineering of the Inner Mongolia Agricultural University, Huhot 010018, China.

Article submitted 05 September 2018. Resubmitted 16 October 2018. Final acceptance 27 October 2018. Final version published as submitted by the authors. 